\title{
Is attention confined to one word at a time? The spatial distribution of parafoveal preview benefits during reading
}

\author{
Chin-An Wang \\ Binghamton University, Binghamton, New York \\ and National Yang-Ming University, Tapei, Taiwan \\ AlbReChT W. INHOFF \\ Binghamton University, Binghamton, New York \\ AND \\ RALPH RADACH \\ Florida State University, Tallahassee, Florida
}

\begin{abstract}
Eye movements were recorded while participants read declarative sentences. Each sentence contained a critical three-word sequence with a three-letter target word $(n)$, a spatially adjacent post-target word $(n+1)$, and a subsequent nonadjacent post-target word $(n+2)$. The parafoveal previews of words $n$ and $n+2$ were manipulated so that they were either fully visible or masked until they were fixated. The results revealed longer word $n$ and word $n+1$ viewing durations when word $n$ had been masked in the parafovea, and this occurred irrespective of whether the target was skipped or fixated. Furthermore, masking of word $n$ diminished the usefulness of the preview of word $n+2$. These results indicate that the effect of a parafoveally available target preview was not strictly localized. Instead, it influenced target viewing and the viewing of the two subsequent words in the text. These results are difficult to reconcile with the assumption that attention is confined to one word at a time until that word is recognized and that attention is then shifted from the recognized word to the next.
\end{abstract}

Readers must select to-be-processed linguistic information from an ordered sequence of concurrently available visual language symbols, and the selection of tobe-recognized words for processing is accompanied by the execution of saccadic eye-movements and by fixations during which useful linguistic information is obtained (see Rayner, 1998, for a detailed review). There is a general consensus that readers regularly obtain useful linguistic information from more than one word during a fixation, typically from the fixated word and from the next parafoveally visible word(s) in the text. Furthermore, linguistic information that is obtained from the parafovea is integrated with information that is acquired during the following fixation, thereby contributing to the fluency of skilled reading. These findings have contributed to the recent development of several types of computational models that provide formal accounts of the coordination of eye-movement programming with text processing (Engbert, Nuthmann, Richter, \& Kliegl, 2005; Feng, 2006; McDonald, Carpenter, \& Shillcock, 2005; Reichle, Pollatsek, Fisher, \& Rayner, 1998; Reilly \& Radach, 2006; Yang, 2006). At the core of these models are assumptions concerning the selection of text segments for linguistic processing and the integration of linguistic information across fixations.

Morrison (1984) proposed a sequential-attention-shift (SAS) assumption according to which readers select a single word for processing and then, after lexical processing has been completed (or has reached a stage near completion), shift attention to the next word in the text. Selection is thus focused at an individual word at each point in time. Saccade programming is assumed to be a relatively timeconsuming process that ensues when the word recognition process has reached threshold, whereas attention shifting is assumed to be instantaneous; therefore, useful information can be acquired from the next word before it is fixated. Morrison's model could also account for the skipping of some words in the text. This is assumed to occur when lexical processing of the next word reaches a critical threshold before the saccade to this word is committed to action. The saccade is then cancelled and is replaced with a saccade to the following word.

Successor models, notably the family of E-Z Reader models (Pollatsek, Juhasz, Reichle, Machacek, \& Rayner, 2008; Pollatsek, Reichle, \& Rayner, 2006; Reichle et al., 1998; Reichle, Pollatsek, \& Rayner, 2006; Reichle, Rayner,

A.W. Inhoff, inhoff@binghamton.edu 
\& Pollatsek, 2003) and EMMA (Salvucci, 2001), have refined SAS assumptions. Specifically, the E-Z Reader model postulates two stages of word recognition (L1 and L2) rather than a single stage, and it assumes that saccade programming and attention shifting are functionally decoupled; that is, the programming of a saccade to the next word is initiated after an attended word's L1 processing is completed, and a corresponding shift of attention occurs when its L2 processing has been completed. Since the duration of saccade programming is typically longer than the L2 duration, the next (parafoveal) word in the text is typically selected for processing before the saccade to it is executed. This yields a preview benefit when the next word is subsequently fixated. The parafoveal preview size for the next word is thus determined completely by the L2 duration of the currently fixated word, according to the E-Z Reader model. The next word can be skipped if its L1 processing is completed relatively early, before the saccade to it is committed to execution. The E-Z Reader model thus decouples saccade programming and attention shifting, although both processes are ultimately controlled by the ease of recognition of an attended word. These refinements have not changed the two key processing assumptions that are common to all SAS models, however: Attention and lexical processing are confined to one word at a time until that word is recognized (often referred to as spotlight assumption; Inhoff, Radach, \& Eiter, 2006), and attention is shifted unidirectionally from one word to the next. These assumptions have remained unchanged for over a quarter of a century.

The main theoretical alternatives to SAS models are processing-gradient (PG) models such as SWIFT (Engbert, Longtin, \& Kliegl, 2002; Engbert et al., 2005) and Glenmore (Reilly \& Radach, 2003, 2006). SWIFT shares some key assumptions with the E-Z Reader model, notably the assumption that word recognition involves the completion of two serial stages, one that involves a rapid rise in the activation of a processed word until its threshold is reached, and one that involves a slower decrease of activation that reaches a zero value when the word is recognized. All PG models differ from SAS models, however, in that they assume that the lexical processing of spatially adjacent words can overlap in time. Moreover, PG models could assume that the gradient can be adjusted in response to processing demands, so that fewer words are included when foveal processing is difficult, although this modification has not yet been implemented in the computational model. Besides, PG models generally posit that saccade generation is independent from but strongly modulated by lexical processing. When programmed, saccades are directed toward the lexical representation with the highest level of activation rather than toward each word in sequence. In spite of their substantial differences, SAS and PG models have yielded equally successful computational simulations of a wide range of data (see Radach, Reilly, \& Inhoff, 2007, for a recent discussion).

Thus far, most empirical examinations of eye-movement control during reading have used SAS mechanisms to predict and accommodate oculomotor effects (Radach et al., 2007), since hypothesized mechanisms are relatively transparent. For instance, if attention is confined to one word until it is recognized and then shifted strictly from one word to the next, the processing of a fixated (foveal) word should not be influenced by the linguistic properties of the next (parafoveal) word in the text. A considerable number of studies have examined the influence of a parafoveally visible word on foveal word processing, some of which have revealed robust parafoveal-on-foveal effects (e.g., Inhoff, Starr, \& Shindler, 2000; Kennedy \& Pynte, 2005; Kliegl, Nuthmann, \& Engbert, 2006). The validity of these effects has been challenged, however, as some proportion of parafoveal-on-foveal effects could have resulted from mislocated fixations (Drieghe, Rayner, \& Pollatsek, 2008; Rayner, Pollatsek, Drieghe, Slattery, \& Reichle, 2007; Rayner, White, Kambe, Miller, \& Liversedge, 2003); that is, the parafoveal word might have influenced the processing of a fixated word because the saccade was directed at the parafoveal word but landed on the prior word instead. Consistent with this claim, Engbert, Nuthmann, and Kliegl (2007) estimated that approximately $15 \%$ of all saccades are "mislocated."

Other tests of the spotlight assumption have examined the range from which useful parafoveal information can be obtained. According to spotlight models, readers obtain useful information from the fixated word and then from the next word in the text only. According to PG models, linguistic information should be obtained routinely from more than one parafoveally visible word (unless the processing of a fixated word is relatively difficult). To test the range of parafoveal information acquisition, Rayner, Juhasz, and Brown (2007) manipulated the parafoveal preview of a nonadjacent word; that is, during the viewing of a critical word ( $n$ ), the word $n+2$ was either visible or masked in the parafovea, and the mask remained in place until the eyes had moved to the right of word $n$, after which it was replaced with word $n+2$. Consistent with the assumptions of SAS models, viewing of word $n+2$ was virtually identical in the word $n+2$ visibility and in the word $n+2$ masking condition, indicating that no useful information had been obtained from a nonadjacent word preview (see also Angele, Slattery, Yang, Kliegl, \& Rayner, 2008); however, other studies have revealed subtle word $n+2$ preview effects (Inhoff, Wang, Solomon, \& Seymour, 2007; Kliegl, Risse, \& Laubrock, 2007; Radach \& Glover, 2007)

The present study used a novel extension of prior work to test the two controversial SAS assumptions - that attention is focused at one word at a time until, and that the recognition of the word must be completed before, the spotlight of attention can be shifted to the next word in the text. This was achieved by manipulating the parafoveal previews of two words (the target word $[n]$ and nonadjacent word $n+2$ ), that were members of a critical three-word sequence. Parafoveal masking of the target should increase the time that is spent viewing it, since no useful target information can be obtained during the $\mathrm{L} 2$ processing of the pretarget word. Parafoveal target masking should not influence the viewing of post-target word $n+1$, however, since the parafoveal masking of the target should not influence the duration of its L2 processing, during which word $n+1$ information can 
be obtained from the parafovea; that is, the viewing of the following word $(n+1)$ should not be influenced by target (word $n$ ) masking.

According to SAS models, skipping of the masked target should not occur, since its L1 processing cannot be completed prior to fixation. Yet oculomotor targeting errors may overshoot the target and result in its pseudoskipping. The resulting mislocated word $n+1$ fixations should be subject to the effects of parafoveal target masking, since the target-masking effect will now be expressed during mislocated word $n+1$ viewings, or pseudoskippings could be corrected with a regression that moves the eyes back to the target. In other words, the deleterious effects of target $\mathrm{n}$ masking must be resolved during the target word's subsequent viewing, when it is fixated, or during post-target word $n+1$ viewing, when the target is skipped. Since target-masking effects need to be resolved before attention can be shifted, SAS models must predict that $\mathrm{n}$ masking of word $n$ cannot influence the acquisition of parafoveal information from word $n+2$, irrespective of whether the target was fixated or skipped.

\section{METHOD}

\section{Participants}

Forty-four Binghamton University undergraduates participated for course credit. All participants were native English speakers, were naive as to the purpose of the experiment, and had normal or corrected-to-normal vision.

\section{Materials}

One hundred forty sentences were constructed, each of which contained a 3-letter target word $(n)$, a spatially adjacent post-target word $(n+1)$ that ranged from 4 to 7 letters $(M=6.0$ letters), and a subsequent nonadjacent post-target word $(n+2)$ that ranged from 4 to 8 letters $(M=5.7$ letters $)$. Figure 1 shows the sample sentence "The overly aggressive tax officer walked into the office to meet with a client" (italics added to show the three critical words).

The boundary technique (Rayner, 1975) was used to manipulate the visibility of words $n$ and $n+2$ until the eyes reached or tra- versed the blank space preceding them. Prior to the eyes' reaching or crossing a boundary, the corresponding words were either visible or masked. A mask had the same shape as its corresponding word, and all masks were pronounceable nonwords (e.g., the pseudoword mekfil masked the word $n+2$, walked, in the sample sentence). Figure 1 shows that the change from the preview to the corresponding word typically occurred during the saccade that crossed the boundary location, as is the case in lines (a) and (b) for word $n$ and lines (c) and (d) for word $n+2$.

\section{Apparatus}

Sentences were presented on a 22 -in. Iiyama CRT monitor at $1,024 \times 768$ resolution, in black text on a light-gray background. The refresh rate was set to $150 \mathrm{~Hz}$. Text was displayed in 12-pt Courier font, with each character occupying 10 pixels horizontally. Sentences were displayed on a single line of text on the horizontal midline of the monitor. The distance from the eyes to the monitor was set at $90 \mathrm{~cm}$, so that each character subtended approximately $.25^{\circ}$ of visual angle. Sentences were viewed with both eyes, though the movements of only the right eye were recorded. Recording was done with an SR Research Eyelink 1000 eyetracker at a sampling rate of $1000 \mathrm{~Hz}$ and with an accuracy of approximately one letter space. The experiment was programmed using Eyelink Experiment Builder software, and Eyelink software was also used to separate the continuously sampled eye movement and position data into fixations (when the eye was stationary), and saccades (when the eye was mobile).

\section{Procedure}

Participants were tested individually in sessions lasting approximately $40 \mathrm{~min}$. A horizontal three-point calibration of the eyetracking system preceded the experiment. This procedure required participants to fixate a sequence of four fixation markers as they appeared in random order at the left, center, and right locations on the horizontal midline of the screen.

After successfully completing the calibration routine, participants were asked to fixate a marker (a plus sign) on the left side of the screen at the horizontal midline of the monitor and to press a button on a game controller. Buttonpresses replaced the marker with a to-be-read sentence. An additional five-letter string, "ooXoo," was shown three character spaces to the right of the sentence period. Participants were instructed to read through the sentence and then to fixate on the uppercase $\mathrm{X}$ before pressing the button once more to clear the screen. The proximity of the last fixation to the upper-

a) The overly aggressive koz officer mekfil into the office to meet with a client.

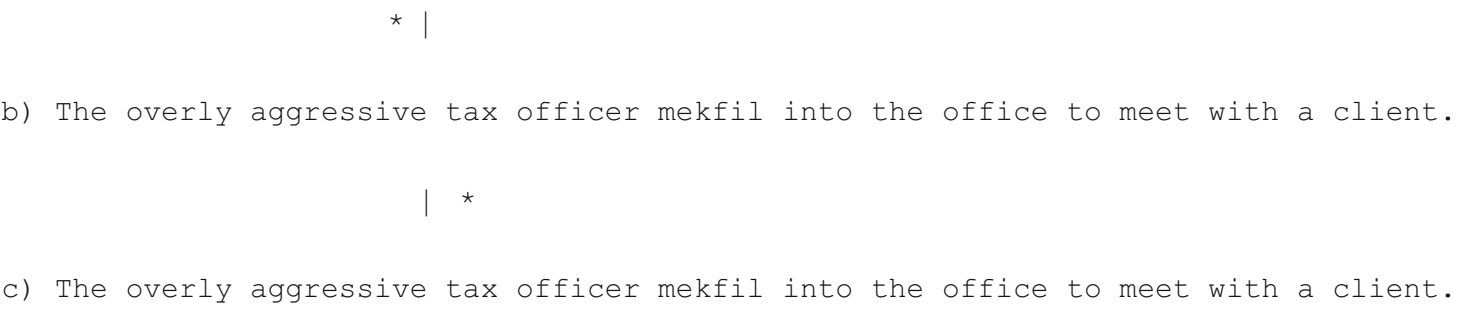

* |

d) The overly aggressive tax officer walked into the office to meet with a client.

Figure 1. Examples of the display-change conditions in the present experiment. The vertical line indicates the position of the display-change-triggering boundary. Each fixation is indicated by an asterisk below the line of text. 
case $\mathrm{X}$ was used to check tracking accuracy during sentence reading, and trials with a landing position that was two or more letters off from the $\mathrm{X}$ location were excluded from the analyses.

Participants were instructed to read sentences silently for comprehension, and they were told that they would be asked questions about sentence content on occasion. To prepare readers for visual-display changes, they were told that the equipment did not always function properly and that flicker on the screen should be ignored as much as possible. All display changes were latched (i.e., they occurred only once, when the eye crossed a predetermined boundary). There was, for instance, no further target-presentation change when the target was refixated or when it was reread a second time. The high rate of eye-position sampling and the high screen-refresh rate allowed for the implementation of display changes within less than $10 \mathrm{msec}$ of a boundary crossing during saccades.

\section{Experimental Design and Data Analysis}

Four lists were created, all of which contained an identical sequence of sentences. The lists differed in that the critical three-word sequence was presented in a different condition on each list. Each list contained 35 items in each experimental condition, and the ordering of conditions was randomized within each list. The assignment of lists to participants was counterbalanced over 4 successive participants.

The Experiment Builder software (www.eyelinkinfo.com) was used to control word $n$ and word $n+2$ visibility during sentence reading, and EDAS II software (Entroware Communication, www.entroware .com) was used to map recorded fixation locations onto text and to compute a wide range of oculomotor measures. In EDAS, a word is considered fixated when the fixation falls on one of its constituent letters or on the blank space preceding it. Skipping rates, regression rates, and two viewing-duration measures were of primary interest. Skipping occurred when a word and the preceding blank space were not fixated during first-pass sentence reading; a regression occurred when the word was fixated with an interword regression. One viewing duration measure, the duration of the first fixation on a critical word, consisted of the duration of the first fixation on a word, irrespective of the number of fixations. Another measure, gaze duration, consisted of the first fixation on a word plus all the remaining time that was spent viewing it until another word was fixated. These two measures are typically used to index visual word recognition (Inhoff \& Radach, 1998). Another supplementary viewing-duration measure, total viewing time, was also computed. It consisted of a word's gaze duration plus the time that was spent rereading it when it was viewed more than once. Total viewing-duration data are shown in the tables, but they were not statistically analyzed in order to avoid an overly redundant reporting of statistical effects. The theoretical significance of total viewing durations is relatively less transparent.

To be included in the analyses of viewing durations, the saccades to and from a critical word had to be right-directed, and fixation durations had to be between $50 \mathrm{msec}$ and $1,000 \mathrm{msec}$. Overall, this resulted in the exclusion of approximately $25 \%$ of the trials. All eyemovement data during word $n, n+1$, and $n+2$ reading were examined via $2($ word $=n$ preview: visible vs. masked $) \times 2($ word $=n+2$ preview: visible vs. masked) within-subjects ANOVAs. Analyses across items were performed when there were at least three data points for each word in each experimental condition.

\section{RESULTS}

\section{Target (Word $n$ ) Reading}

Oculomotor activity for target reading is shown in Table 1 as a function of target (word $n$ ) and nonadjacent post-target (word $n+2$ ) visibility.

All models predict that parafoveal masking of the target will hamper its processing. Examination of skipping rates showed that target skipping occurred 7\% less often when its preview was masked $\left[F_{1}(1,43)=20.53, p<\right.$ $\left..001 ; F_{2}(1,139)=18.32, p<.001\right]$. Target skipping in the target-masking condition was not a rarity, however. Instead, it occurred on $25 \%$ of the trials. All other skipping effects were negligible $(p>.25)$.

The relative frequency of regressions to the target was also a function of target masking, with more regressions when the target's preview had been masked prior to skipping $(33 \%)$ than when it had been visible $(21 \%)$ $\left[F_{1}(1,43)=11.03, p<.01 ; F_{2}(1,139)=57.06, p<.01\right]$. All other regression effects were negligible $(p>.4)$.

Target-viewing durations revealed the familiar pattern of parafoveal preview effects. When the target word was fixated, less viewing time was spent when it had been visible in the parafovea than when it had been masked [firstfixation duration $F_{1}(1,43)=58.29, p<.01 ; F_{2}(1,139)=$ $116.02, p<.01$, and gaze duration $F_{l}(1,43)=68.43, p<$ $\left..01 ; F_{2}(1,139)=167.64, p<.01\right]$. All other target effects were negligible $(p>.4)$.

\section{Reading of the Spatially Adjacent \\ Post-Target Word $(n+1)$}

Oculomotor activity during word $n+1$ reading is shown in Table 2 as a function of word $n$ and word $n+2$ visibility.

Word $n+1$ was skipped rarely (6.5\%), and its skipping was slightly more common when the target word had been

Table 1

Word $\boldsymbol{n}$ Reading As a Function of Its Parafoveal Visibility and the Visibility of Word $\boldsymbol{n}+2$

\begin{tabular}{|c|c|c|c|c|c|c|c|c|}
\hline \multirow[b]{3}{*}{ Measure } & \multicolumn{4}{|c|}{ Identical Preview of Word $n$} & \multicolumn{4}{|c|}{ Nonword Preview of Word $n$} \\
\hline & \multicolumn{2}{|c|}{$\begin{array}{c}\text { Identical } \\
\text { Preview of } \\
\text { Word } n+2\end{array}$} & \multicolumn{2}{|c|}{$\begin{array}{c}\text { Nonword } \\
\text { Preview of } \\
\text { Word } n+2\end{array}$} & \multicolumn{2}{|c|}{$\begin{array}{c}\text { Identical } \\
\text { Preview of } \\
\text { Word } n+2\end{array}$} & \multicolumn{2}{|c|}{$\begin{array}{c}\text { Nonword } \\
\text { Preview of } \\
\text { Word } n+2\end{array}$} \\
\hline & $M$ & $\overline{S E M}$ & $M$ & $\overline{S E M}$ & $M$ & $\overline{S E M}$ & $M$ & $S E M$ \\
\hline First-fixation duration & 271 & 7 & 268 & 6 & 310 & 8 & 307 & 8 \\
\hline Gaze duration & 291 & 8 & 289 & 7 & 341 & 9 & 341 & 10 \\
\hline Total viewing duration & 319 & 10 & 319 & 9 & 369 & 9 & 373 & 12 \\
\hline Skipping rate & 33 & 2.6 & 33 & 2.3 & 26 & 2.2 & 26 & 2.4 \\
\hline $\begin{array}{l}\text { Regression rate with first-pass } \\
\text { skipping of pretarget word }\end{array}$ & 20 & 3.0 & 23 & 3.5 & 34 & 3.9 & 33 & 3.9 \\
\hline
\end{tabular}

Note-First-fixation duration, gaze duration, and total viewing duration are reported in msec. Skipping rates and regression rates are reported as a percentage of trials on which these oculomotor responses occurred. 
Table 2

Word $n+1$ Reading When the Word $n$ Was Skipped As a Function of the Word $n$ and Word $n+2$ Visibility

\begin{tabular}{|c|c|c|c|c|c|c|c|c|}
\hline \multirow[b]{3}{*}{ Measure } & \multicolumn{4}{|c|}{ Identical Preview of Word $n$} & \multicolumn{4}{|c|}{ Nonword Preview of Word $n$} \\
\hline & \multicolumn{2}{|c|}{$\begin{array}{c}\text { Identical } \\
\text { Preview of } \\
\text { Word } n+2\end{array}$} & \multicolumn{2}{|c|}{$\begin{array}{l}\text { Nonword } \\
\text { Preview of } \\
\text { Word } n+2\end{array}$} & \multicolumn{2}{|c|}{$\begin{array}{c}\text { Identical } \\
\text { Preview of } \\
\text { Word } n+2\end{array}$} & \multicolumn{2}{|c|}{$\begin{array}{l}\text { Nonword } \\
\text { Preview of } \\
\text { Word } n+2\end{array}$} \\
\hline & $M$ & $S E M$ & $M$ & $\overline{S E M}$ & $M$ & $\overline{S E M}$ & $M$ & SEM \\
\hline First-fixation duration & 272 & 8 & 282 & 10 & 312 & 10 & 315 & 12 \\
\hline Gaze duration & 409 & 20 & 404 & 19 & 456 & 19 & 479 & 24 \\
\hline Total viewing duration & 458 & 22 & 446 & 18 & 521 & 23 & 528 & 26 \\
\hline Skipping rate & 6.8 & 1.1 & 7.0 & 1.1 & 6.0 & 1.0 & 6.0 & 1.0 \\
\hline $\begin{array}{l}\text { Regression rate with first-pass } \\
\text { skipping of pretarget word }\end{array}$ & 13 & 1.4 & 20 & 1.9 & 12 & 1.3 & 18 & 1.8 \\
\hline
\end{tabular}

Note-First-fixation duration, gaze duration, and total viewing duration are reported in msec. Skipping rates and regression rates are reported as a percentage of trials on which these oculomotor responses occurred.

visible than when it had been masked $\left[F_{1}(1,37)=2.05\right.$, $\left.p=.159 ; F_{2}(1,139)=5.24, p<.05\right]$. All other skipping effects were negligible $(p>.4)$. Regressions to word $n+1$ were also relatively rare $(6 \%)$, and their frequency was determined by the masking of word $n+2$ (i.e., regressions to word $n+1$ were more common when word $n+2$ was masked) $\left[F_{1}(1,139)=30.57, p<.01 ; F_{2}(1,139)=33.26\right.$, $p<.01]$. None of the remaining fixation frequency effects approached significance (all $p \mathrm{~s}>.1$ ).

Fixations on word $n+1$ after the skipping of a masked target word could have been misplaced. In response to this, readers could have sought to identify the target while word $n+1$ was fixated or they could have regressed toward the target. Consistent with this possibility, firstfixation and gaze durations on the target word were longer when a masked target word was skipped $\left[F_{1}(1,37)=\right.$ $\left.17.79, p<.01 ; F_{2}(1,78)=13.68, p<.01\right]$ than when a visible target word was skipped $\left[F_{1}(1,37)=13.07, p<\right.$ $\left..01 ; F_{2}(1,78)=16.86, p<.01\right]$. All other effects were negligible (all $p \mathrm{~s}>.15$ ).

Table 3 shows readers' oculomotor activity during word $n+1$ reading when the target word was fixated. SAS and PG models make fundamentally different predictions. According to SAS models, target masking should not influence word $n+1$ viewing when the target is fixated, since target masking does not influence the duration of its L1 and L2 processing (and hence the usefulness of word $n+1$ prior to the fixation of word $n+1$ is unchanged). According to PG models, the effects of target masking can be spa- tially distributed and thus influence target and post-target processing. Consistent with this prediction, more time was spent viewing word $n+1$ when the previously fixated target had been masked. The corresponding statistical effect was marginally reliable for first-fixation durations $\left[F_{1}(1,43)=2.57, p<.12 ; F_{2}(1,124)=2.52, p<.12\right]$, and highly reliable for gaze durations $\left[F_{1}(1,43)=16.11\right.$, $\left.p<.01 ; F_{2}(1,124)=6.03, p \mathrm{~s}<.01\right]$.

\section{Reading of the Spatially Nonadjacent Post-Target Word $(n+2)$}

Oculomotor activity during word $n+2$ viewing is shown in Table 4 as a function of word $n$ and word $n+2$ visibility.

According to SAS models, the usefulness of a spatially nonadjacent word $n+2$ preview should not be influenced by the parafoveal visibility of the target word, irrespective of whether the target word was skipped or fixated, because the L2 duration of word $n+1$-during which useful information can be obtained from a parafoveally visible word $n+2$ - does not change across conditions. PG models, by contrast, allow for spatially distributed target-masking effects. Specifically, the allocation of less attention to word $n+1$ in response to target masking may diminish the extraction of parafoveally visible word $n+2$ information. Consistent with PG models but not with SAS models, less useful information was obtained from a word $n+2$ preview when the target word had been masked than when it had been visible. The corresponding interaction

Table 3

Word $n+1$ Reading When the Word $n$ Has Been Fixated As a Function of the Word $n$ and Word $n+2$ Visibility

\begin{tabular}{|c|c|c|c|c|c|c|c|c|}
\hline \multirow[b]{3}{*}{ Measure } & \multicolumn{4}{|c|}{ Identical Preview of Word $n$} & \multicolumn{4}{|c|}{ Nonword Preview of Word $n$} \\
\hline & \multicolumn{2}{|c|}{$\begin{array}{c}\text { Identical } \\
\text { Preview of } \\
\text { Word } n+2 \\
\end{array}$} & \multicolumn{2}{|c|}{$\begin{array}{c}\text { Nonword } \\
\text { Preview of } \\
\text { Word } n+2\end{array}$} & \multicolumn{2}{|c|}{$\begin{array}{c}\text { Identical } \\
\text { Preview of } \\
\text { Word } n+2 \\
\end{array}$} & \multicolumn{2}{|c|}{$\begin{array}{c}\text { Nonword } \\
\text { Preview of } \\
\text { Word } n+2 \\
\end{array}$} \\
\hline & $M$ & $\overline{S E M}$ & $M$ & $\overline{S E M}$ & $M$ & $\overline{S E M}$ & $M$ & SEM \\
\hline First-fixation duration & 267 & 5 & 279 & 6 & 281 & 6 & 278 & 7 \\
\hline Gaze duration & 319 & 9 & 330 & 9 & 345 & 8 & 345 & 9 \\
\hline Total viewing duration & 353 & 11 & 392 & 12 & 378 & 12 & 399 & 12 \\
\hline
\end{tabular}

Note-First-fixation duration, gaze duration, and total viewing duration are reported in msec. 
Table 4

Reading of the Spatially Nonadjacent Post-Target Word $n+2$ As a Function of the Visibility of Word $n$ and Word $n+2$

\begin{tabular}{|c|c|c|c|c|c|c|c|c|c|c|}
\hline \multirow[b]{3}{*}{ Measure } & \multicolumn{5}{|c|}{ Identical Preview of Word $n$} & \multicolumn{5}{|c|}{ Nonword Preview of Word $n$} \\
\hline & \multicolumn{2}{|c|}{$\begin{array}{c}\text { Identical } \\
\text { Preview of } \\
\text { Word } n+2\end{array}$} & \multicolumn{2}{|c|}{$\begin{array}{l}\text { Nonword } \\
\text { Preview of } \\
\text { Word } n+2\end{array}$} & \multirow[b]{2}{*}{ Benefit } & \multicolumn{2}{|c|}{$\begin{array}{c}\text { Identical } \\
\text { Preview of } \\
\text { Word } n+2\end{array}$} & \multicolumn{2}{|c|}{$\begin{array}{c}\text { Nonword } \\
\text { Preview of } \\
\text { Word } n+2\end{array}$} & \multirow[b]{2}{*}{ Benefi } \\
\hline & $M$ & $S E M$ & $M$ & $S E M$ & & $M$ & SEM & $M$ & $S E M$ & \\
\hline First-fixation duration & 257 & 4 & 300 & 6 & 43 & 263 & 6 & 292 & 7 & 29 \\
\hline Gaze duration & 288 & 5 & 342 & 7 & 54 & 304 & 7 & 337 & 7 & 33 \\
\hline Skipping rate & 11.0 & 1.4 & 6.8 & 1.2 & - & 11.0 & 1.5 & 6.6 & 1.1 & - \\
\hline $\begin{array}{l}\text { Regression rate with first-pass } \\
\text { skipping of pretarget word }\end{array}$ & 8.0 & 1.0 & 9.3 & 1.2 & - & 9.4 & 1.1 & 7.9 & 1.1 & - \\
\hline
\end{tabular}

Note-First-fixation duration, gaze duration, and total viewing duration are reported in msec. Skipping rates and regression rates are reported as a percentage of trials on which these oculomotor responses occurred.

of word $n$ with word $n+2$ visibility effects was marginally reliable for first-fixation durations $\left[F_{1}(1,43)=3.26\right.$, $\left.p=.077 ; F_{2}(1,97)=1.82, p=.18\right]$, and reliable for gaze durations $\left[F_{1}(1,43)=5.08, p<.05 ; F_{2}(1,97)=5.46, p<\right.$ $.025]$ (see Figure 2).

The main effect of target preview did not approach significance in any of the analyses (all $p \mathrm{~s}>.12$ ). As expected, the main effect of word $n+2$ visibility was highly reliable, with shorter word $n+2$ viewing durations when a parafoveal preview had been available [first fixation durations, $F_{1}(1,43)=38.80, p<.01 ; F_{2}(1,97)=69.57$, $p<.01$, and gaze durations, $F_{1}(1,43)=53.96, p<.01$; $F_{2}(1,97)=67.45$, all $p$ s $\left.<.01\right]$.

\section{DISCUSSION}

The main goal of the present study was to determine whether the lexical processing of a word must be completed before attention can be shifted from one word to the next, as is maintained by SAS models of eye-movement control during reading. PG models offer a theoretical alternative in which the linguistic processing of spatially adjacent words can overlap in time. To determine whether the processing of the next word in the text is conditional upon the completion of the lexical processing of the prior word, the present study manipulated the parafoveal visibility of two nonadjacent words, the target word $n$ and the post-target word $n+2$. Both theoretical conceptions can explain the effects of target masking on target-word viewing and on the viewing of the spatially adjacent word $n+1$ when word $n$ is skipped. PG models can also accommodate effects of target masking on word $n+1$ reading when the target has been fixated, however; most importantly, they can accommodate the effects of target masking on the usefulness of parafoveally visible word $n+2$ previews.

The present results reveal robust main effects of parafoveal word $n$ and word $n+2$ masking on word $n$ and word $n+2$ viewing. More time was spent viewing each one of the two words when they were masked prior to fixation than when they had been visible in the parafovea, a finding that is consistent with earlier work, and the skipping of a relatively short target word was more common in the parafoveal preview condition than in the masking condi- tion (see Rayner, 1998, for a review of similar findings). These findings are in general agreement with both SAS and PG models.

The target-skipping data also reveal that there was a considerable proportion of trials on which a masked target was skipped, even though no useful L1 processing of the target could have been performed on these trials. To account for this finding, SAS models must assume either that the target skipping was erroneous (and that the following fixation was mislocated) or that the processing of the pseudoword preview resulted in the completion of some preliminary processing that was mistaken for the completion of the target's L1 processing. Consistent with these accounts, the skipping of a masked target word increased the viewing duration on the post-target word $n+1$, and regressions toward a skipped target were more common when it had been masked in the parafovea. PG models can also account for these findings. Masking of the target will increase its processing difficulty and attract attentionhence the higher rate of regression toward the target - and it will diminish the resources for word $n+1$ processing hence longer word $n+1$ viewing durations.

Other findings favor the assumptions of the PG model over those of the spotlight-processing model. Specifically, target-word visibility influenced word $n+1$ skipping and the viewing duration of word $n+1$, even when the target had been fixated. According to SAS models, all effects of

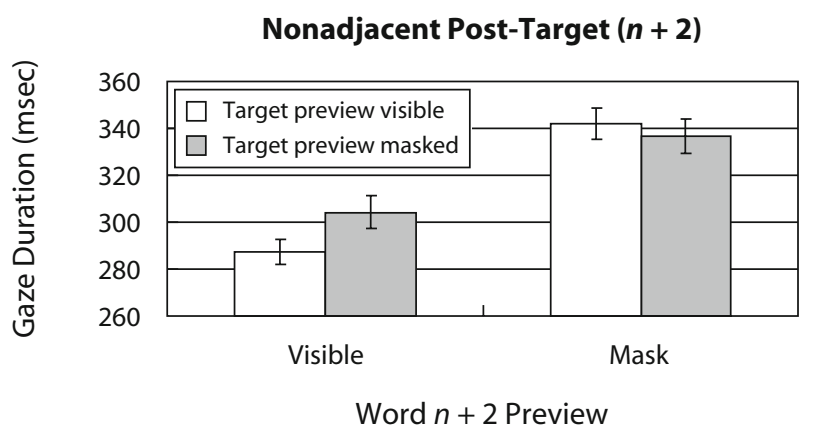

Figure 2. Word $n+2$ gaze duration as a function of the preview of words $n$ and $n+2$. 
parafoveal target masking should be resolved during target viewing when the word has been fixated, or during posttarget viewing when the target has been skipped. The effect of the target's parafoveal visibility on word $n+1$ skipping and on the gaze duration of word $n+1$, irrespective of whether the target was fixated or not, are thus difficult to explain on this basis. Furthermore, the parafoveal visibility of the target word influenced the acquisition of useful information from nonadjacent post-target word $n+2$. Consistent with PG models, these findings indicate that the effect of parafoveal target masking was not confined to the processing of the target. Instead, target masking also diminished the effectiveness with which the next word $(n+1)$ was recognized and with it the acquisition of parafoveal word $n+2$ information during word $n+1$ viewing.

This evidence against central SAS assumptions is more robust than earlier findings, since mislocated fixationswhich have been used to account for parafoveal-on-fovea effects (Rayner et al., 2003) - cannot provide a viable alternative account. Minor modifications of SAS assumptions could improve the flexibility of this class of models and account for a subset of the findings. Specifically, SAS models could assume that attention-based selection for processing is error prone. Similar to oculomotor targeting errors, attention-based selection for processing may also over- or underreach the next word in the text. When a word is relatively long, attentional selection may not always encompass the full word, and when it is relatively short, attentional selection may extend beyond a single word and there can be overlap in the foci of successive areas of attention. With this added assumption, deleterious effects of the parafoveal masking of a short target word may extend into post-target $(n+1)$ viewing. Parafoveal target masking could thus influence word $n+1$ viewing, even when the target was fixated. This ad hoc assumption cannot explain the effect of the target's parafoveal visibility on the usefulness of word $n+2$ previews, as erroneous target-selection effects should not influence the L1 and L2 processing of word $n+1$ and thus leave the acquisition of parafoveal word $n+2$ unchanged.

Major theoretical debates are rarely decided by a single empirical finding. The present data do not stand alone but extend and reinforce established findings. Using a novel modification of the boundary technique, our study has provided additional evidence that favors an account in which attention-based selection can extend beyond an individual word, especially when that word is short, and it rules out a previously applied alternative account. It now appears exceedingly unlikely that previously reported linguistic word $n-1$ and word $n+1$ effects on word $n$ viewing can be attributed exclusively to oculomotor targeting errors.

\section{AUTHOR NOTE}

This research was supported by National Institutes of Health Grant HD043405. The project was completed while the first author was on a research visit at Binghamton University with a Fulbright scholarship. We thank Mallory Bersamira and Jing Li for the construction of materials and the collection of data. Correspondence concerning this article should be addressed to A. W. Inhoff, Department of Psychology, Bing- hamton University, Binghamton, NY 13902-6000 (e-mail: inhoff@, binghamton.edu).

\section{REFERENCES}

Angele, B., Slattery, T. J., Yang, J., Kliegl, R., \& Rayner, K. (2008). Parafoveal processing in reading: Manipulating $n+1$ and $n+2$ previews simultaneously. Visual Cognition, 16, 697-707.

Drieghe, D., Rayner, K., \& Pollatsek, A. (2008). Mislocated fixations can account for parafoveal-on-foveal effects in eye movements during reading. Quarterly Journal of Experimental Psychology, 61, 1239-1249.

Engbert, R., Longtin, A., \& Kliegl, R. (2002). A dynamical model of saccade generation in reading based on spatially distributed lexical processing. Vision Research, 42, 621-636.

Engbert, R., Nuthmann, A., \& Kliegl, R. (2007) An iterative algorithm for the estimation of the distribution of mislocated fixations during reading. In R. P. G. van Gompel, M. H. Fischer, W. S. Murray, \& R. L. Hill (Eds.), Eye movements: A window on mind and brain (pp. 319-337). Amsterdam: Elsevier.

Engbert, R., Nuthmann, A., Richter, E. M., \& Kliegl, R. (2005). SWIFT: A dynamical model of saccade generation during reading. Psychological Review, 112, 777-813.

FenG, G. (2006). Eye movements as time-series random variables: A stochastic model of eye movement control in reading. Cognitive Systems Research, 7, 70-95.

INHOFF, A. W., \& RADACH, R. (1998). Definition and computation of oculomotor measures in the study of cognitive processes. In G. Underwood (Ed.), Eye guidance in reading and scene perception (pp. 2954). Amsterdam: Elsevier.

InHoff, A. W., RADACH, R., \& EITER, B. (2006). Temporal overlap in the linguistic processing of successive words in reading: Reply to Pollatsek, Reichle, and Rayner (2006a). Journal of Experimental Psychology: Human Perception \& Performance, 32, 1490-1495.

Inhoff, A. W., Starr, M., \& Shindler, K. L. (2000). Is the processing of words during eye fixations in reading strictly serial? Perception \& Psychophysics, 62, 1474-1484.

Inhoff, A. W., Wang, C.-A., Solomon, M. J., \& Seymour, B. A. (2007, November). Is word processing during reading strictly serial? Evidence from preview benefits of $n+2$. Poster presented at the annual meeting of the Psychonomic Society, Long Beach, CA.

Kennedy, A., \& Pynte, J. (2005). Parafoveal-on-foveal effects in normal reading. Vision Research, 45, 153-168.

Kliegl, R., Nuthmann, A., \& Engbert, R. (2006). Tracking the mind during reading: The influence of past, present, and future words on fixation durations. Journal of Experimental Psychology: General, $\mathbf{1 3 5}, 12-35$.

Kliegl, R., Risse, S., \& Laubrock, J. (2007). Preview benefit and parafoveal-on-foveal effects from word $n+2$. Journal of Experimental Psychology: Human Perception \& Performance, 33, 1250-1255.

McDonald, S. A., Carpenter, R. H. S., \& Shillcock, R. C. (2005). An anatomically constrained, stochastic model of eye movement control in reading. Psychological Review, 112, 814-840.

Morrison, R. E. (1984). Manipulation of stimulus onset delay in reading: Evidence for parallel programming of saccades. Journal of Experimental Psychology: Human Perception \& Performance, 10, 667-682.

Pollatsek, A., Juhasz, B. J., Reichle, E. D., Machacek, D., \& RAYNER, K. (2008). Immediate and delayed effects of word frequency and word length on eye movements in reading: A reversed delayed effect of word length. Journal of Experimental Psychology: Human Perception \& Performance, 34, 726-750.

Pollatsek, A., Reichle, E. D., \& Rayner, K. (2006). Tests of the E-Z Reader model: Exploring the interface between cognition and eyemovement control. Cognitive Psychology, 52, 1-56.

Radach, R., \& Glover, L. M. (2007, August). Exploring the limits of spatially distributed word processing in normal reading: A new look at $n-2$ preview effects. Paper presented at the European Conference on Eye Movements, Potsdam, Germany.

RadaCh, R., ReILly, R. [G.], \& InHOFF, A.W. (2007). Models of oculomotor control in reading: Toward a theoretical foundation of current debates. In R. P. G. van Gompel, M. H. Fischer, W. S. Murray, \& R. L. 
Hill (Eds.), Eye movements: A window on mind and brain (pp. 237269). Amsterdam: Elsevier.

RAYNER, K. (1975). The perceptual span and peripheral cues in reading. Cognitive Psychology, 7, 65-81.

RAYNER, K. (1998). Eye movements in reading and information processing: 20 years of research. Psychological Bulletin, 124, 372-422.

Rayner, K., Juhasz, B. J., \& Brown, S. J. (2007). Do readers obtain preview benefit from word $n+2$ ? A test of serial attention shift versus distributed lexical processing models of eye movement control in reading. Journal of Experimental Psychology: Human Perception \& Performance, 33, 230-245.

Rayner, K., Pollatsek, A., Drieghe, D., Slattery, T. J., \& Reichle, E. D. (2007). Tracking the mind during reading via eye movements: Comments on Kliegl, Nuthmann, and Engbert (2006). Journal of Experimental Psychology: General, 136, 520-529.

Rayner, K., White, S. J., Kambe, G., Miller, B., \& Liversedge, S. P. (2003). On the processing of meaning from parafoveal vision during eye fixations in reading. In J. Hyönä, R. Radach, \& H. Deubel (Eds.), The mind's eye: Cognitive and applied aspects of eye movement research (pp. 213-234). Amsterdam: Elsevier.

Reichle, E. D., Pollatsek, A., Fisher, D. L., \& Rayner, K. (1998). Toward a model of eye movement control in reading. Psychological Review, 105, 125-157.
Reichle, E. D., Pollatsek, A., \& Rayner, K. (2006). E-Z Reader: A cognitive-control, serial-attention model of eye-movement behavior during reading. Cognitive Systems Research, 7, 4-22.

Reichle, E. D., Rayner, K., \& Pollatsek, A. (2003). The E-Z Reader model of eye-movement control in reading: Comparisons to other models. Behavioral \& Brain Sciences, 26, 445-526.

REILly, R. G., \& RADACH, R. (2003). Foundations of an interactive activation model of eye movement control in reading. In J. Hyönä, R. Radach, \& H. Deubel (Eds.), The mind's eye: Cognitive and applied aspects of eye movement research (pp. 429-456). Amsterdam: Elsevier.

REILLY, R. G., \& RADACH, R. (2006). Some empirical tests of an interactive activation model of eye movement control in reading. Cognitive Systems Research, 7, 34-55.

SAlvucci, D. D. (2001). An integrated model of eye movements and visual encoding. Cognitive Systems Research, 1, 201-220.

YANG, S.-N. (2006). An oculomotor-based model of eye movements in reading: The competition/interaction model. Cognitive Systems Research, 7, 56-69.

(Manuscript received January 22, 2009;

revision accepted for publication April 28, 2009.) 